\title{
Desmitis of the Accessory Ligament of the Equine Deep Digital Flexor Tendon: A Regenerative Approach
}

\author{
Charlotte Beerts ${ }^{1}$, Charlotte Seifert ${ }^{2}$, Marieke Zimmerman ${ }^{3}$, Eduardo Felix ${ }^{2}$, Marc Suls ${ }^{3}$, Tom Mariën ${ }^{1}$, Sarah Broeckx ${ }^{4}$ and Jan H Spaas $^{4 *}$
}

${ }^{1}$ Equitom Equine Hospital, Venusbergstraat 1, Belgium

${ }^{2}$ Equine Sport Veterinary, Avenue Belle Vue 98, Belgium

${ }^{3}$ Equine Veterinary Practice Kazernelaan 144, The Netherlands

${ }^{4}$ Global Stem Cell Technology, Geeneindestraat 1, B-3560 Meldert-Lummen, Belgium

\begin{abstract}
Background: Desmitis of the accessory ligament of the deep digital flexor tendon (ALDDFT) is a very common problem in different breeds of sport horses, with an inability to heal adequately after conservative therapy in many cases. However, the treatment of different kinds of tendon lesions with platelet-rich plasma (PRP), mesenchymal stem cells (MSCs), or even tenogenic induced MSCs have been reported with promising results.
\end{abstract}

Methods: After MSC and PRP isolation of the peripheral blood (PB) of a donor horse, tenogenic induction of the MSCs (Tendo-Cell ${ }^{\circledR}$ ) was confirmed, and samples were microbiologically tested and frozen. Adverse and clinical effects (macroscopic noticeable swelling, lameness and ultrasound imaging) of PRP $(n=4)$, or Tendo-Cell ${ }^{\circledR}(n=4)$ were evaluated after a single intralesional injection in the ALDDFT in 8 horses. For each case, two independent veterinary practitioners were asked to give a score from $0-5$, at approximately 6 weeks and 4 months after treatment $(0=$ no ultrasonographic improvement and $5=90-100 \%$ improvement, or (nearly) no ultrasonographic abnormalities, the ligament has (almost) no hypo-echoic foci, and (nearly) the same fiber orientation as the contralateral ligament).

Results: At approximately 6 weeks post injection, the ultrasound images of all 4 horses treated with PRP only slightly improved. Therefore, a score $2 / 5$ was given by the two attending veterinarians to all 4 patients. In the TendoCell ${ }^{\otimes}$ treated group, on the other hand, all 4 horses received a score $4 / 5$ by the same veterinarians at 6 weeks after intralesional injection. This implicates that the lesions improved about $80 \%$ on the ultrasound images, which was much better than the $40 \%$ improvement in the PRP treated group.

Conclusion: This study reports a positive clinical and ultrasonographical outcome after tenogenic induced MSC (Tendo-Cell ${ }^{\circledR}$ ) treatment of desmitis of the equine ALDDFT, whereas no considerable improvements could be noticed after treatment with allogenic PRP.

\section{Keywords: Allogenic; Stem cells; PRP; Horse; ALDDFT}

\section{Introduction}

Tendon and ligament lesions are a major issue in equine medicine. They are often career ending injuries in high level sport horses, as well as in recreation horses. These lesions can occur after an acute trauma, or they can be the consequence of an accumulation of micro-lesions caused by repeated stresses [1,2]. After the acute rupture of the tissue, there is a first inflammatory phase that can last up to two weeks, and that appears as an hypo- or anechoic region on the ultrasound (intralesional haemorrhage) [3]. It is important to minimize this inflammatory reaction, in order to avoid excessive tissue damage. Following this first phase, there is a repair phase during which scar tissue is formed by fibroblasts [4], and which reaches its peak up to 4 weeks after the initial lesion. This tissue is mostly composed by smaller, less organized, less elastic and weaker fibrils (type III collagen), than the original fibrils (type I collagen) [5]. Finally, there is a maturation phase lasting approximately 6 months. During this phase, type I collagen will increase and partially replace the disordered type III collagen. Controlled exercise is primordial during this phase, in order to encourage the parallel alignment of the fibrils, and subsequently increase the resistance of the tendon [6]. Ultrasound follow-up during this phase is an important aid, in order to define the amount of exercise allowed, depending on the alignment of the collagen fibrils. Despite the maturation, the injured tissue never regains the same structure, strength and elasticity as before, and unfortunately, a substantial number of horses are never able to compete at their initial level again
[7]. Therefore, regenerative therapies are finding their way through the medical landscape $[2,5,8]$.

The accessory ligament of the deep digital flexor tendon (ALDDFT), also named carpal check ligament or distal check ligament, continues the palmar carpal ligament and joins the deep digital flexor tendon (DDFT), in the central one third of the metacarpal region (Figures 1 and 2). The ALDDFT and the superficial digital flexor tendon (SDFT) are bound by fibrous bundles, and this connection predisposes development of adhesions between both structures, in cases of severe lesions and inflammation (desmitis) of one of both structures. Dyson and Ross [1] described that desmitis of the ALDDFT, which is rather uncommonly reported, is a very common problem in the following disciplines: show hunters, show jumpers, dressage horses, polo ponies, American Saddlebred and other trotting breeds, Arabian and halfArbian show horses, driving horses and finally, competition ponies [1].

*Corresponding author: Jan $\mathrm{H}$ Spaas, Global Stem Cell Technology, Geeneindestraat 1, Belgium, Tel: +32 135561 06; Fax: +32 135561 07; E-mail: janspaas@gst.be

Received March 02, 2013; Accepted March 26, 2013; Published April 08, 2013

Citation: Beerts C, Seifert C, Zimmerman M, Felix E, Suls M, et al. (2013) Desmitis of the Accessory Ligament of the Equine Deep Digital Flexor Tendon: A Regenerative Approach. J Tissue Sci Eng 4: 125. doi:10.4172/2157-7552.1000125

Copyright: $\odot 2013$ Beerts C, et al. This is an open-access article distributed under the terms of the Creative Commons Attribution License, which permits unrestricted use, distribution, and reproduction in any medium, provided the original author and source are credited. 


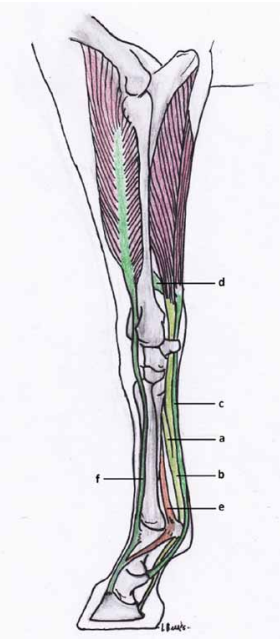

Figure 1: Lateral view of the left thoracic limb with the following structures: (a) the accessory ligament of the deep digital flexor tendon (carpal check ligament), (b) the deep digital flexor tendon, (c) the superficial digital flexor tendon, (d) the accessory ligament of the superficial digital flexor tendon (radial check ligament), (e) the suspensory ligament, and (f) the common digital extensor tendon.

Moreover, the incidence of ALDDFT desmitis is also high in cross-bred and pleasure horses [1].

Horses with acute desmitis of the ALDDFT usually present with a history of sudden onset moderate to severe lameness. Moreover, the proximal one third of the metacarpal region is usually swollen and warm, and palpation of this region is painful. The lameness usually improves after subcarpal nerve blocks [1]. A valuable and practical tool to confirm the diagnose remains ultrasonography. A decrease in echogenicity of the ligament can be noticed, and in most cases, the ligament shows a lack of circumscribed margins.

To date, different conservative treatments have been described for the treatment of tendinitis, such as Non-Steroidal Anti-Inflammatory Drugs (NSAIDs), cooling, box rest and bandaging in humans and horses [9-12]. However, all these treatments only focus on the antiinflammatory or remodelling effect. Moreover, a study of extracorporal shock wave therapy for the treatment of ALDDFT desmitis in 8 Thoroughbred horses did not report a significant healing enhancement [13]. Another suggested treatment is intra-lesional injection of B-aminopropionitrile (Bapten ${ }^{\circledR}$ ); however, some studies suggest a negative effect on equine tendons after a treatment with Bapten ${ }^{\circledR}$ $[1,14]$. As a last resort, in chronic cases, a complete desmotomy of the check ligament has been described in horses, as well [15]. Nevertheless, restitutio ad integrum (restitution of tissue integrity) can never be achieved using this technique. In this regard, tendinitis of the superficial digital flexor tendon (SDFT) and desmitis of the suspensory ligament (SL) have been treated with promising results with platelet-rich plasma (PRP) [16,17], mesenchymal stem cells (MSCs) [18,19], or even tenogenic induced MSCs [20] in horses. However, to our knowledge, besides one horse treated with autologous conditioned plasma [21], there are no reports about any regenerative approach for the treatment of desmitis of the ALDDFT to date.

For all the aforementioned reasons, the present paper describes 2 regenerative treatments of acute desmitis of the ALDDFT in 8 horses. Four horses were intralesionally injected with PRP, and another 4 with allogenic tenogenic induced peripheral blood (PB)-derived MSCs $\left(\right.$ Tendo-Cell ${ }^{\circledR}$ ).

\section{Materials and Methods}

\section{Isolation and tenogenic induction of mesenchymal stem cells (MSCs)}

In total, $50 \mathrm{ml}$ of peripheral blood (PB) was collected in sterile EDTA tubes from the vena jugularis of a 6-years-old donor, gelding for mesenchymal stem cell (MSC) isolation. At the same time, serum was collected and sent to Böse laboratory (Harsum, Germany), for testing on the following transmittable diseases: Equine infectious anemia (EIA), Equine rhinopneumonia (EHV-1, EHV-4), Equine Viral Arteritis (EVA), West-Nile Virus (WNV), African Horse Sickness (AHS), Dourine (Trypanosoma), Piroplasmosis, Malleus, Glanders, Equine Influenza A (equi I and II, American and European type) and Borreliosis (Borrelia burgdorferi, the Lyme disease). Three weeks later, a second blood sample was sent to Böse again, in order to confirm if antibody production was due to vaccination. This confirmed that the donor horse was vaccinated for EHV-1, EHV-4 and Equine Influenza. After arriving in the lab, the $50 \mathrm{ml}$ of blood was centrifuged at $1000 \mathrm{~g}$ for 20 minutes, and the buffy coat was collected and diluted 1:2 with phosphate-buffered saline (PBS). The further isolation, tenogenic induction and Tendo-Cell ${ }^{\circledR}$ production (1 $\mathrm{ml}$ per sample) was performed, as previously described [20].

\section{Preparation of platelet-rich plasma (PRP)}

In total, $300 \mathrm{ml}$ of peripheral blood was taken in a citrate phosphate dextrose adenine-1 (CPDA-1) single blood bag $\left(\right.$ Terumo $\left.{ }^{\circledR}\right)$, for plateletrich plasma (PRP) preparation. From this donor horse, 25 samples of 1 $\mathrm{ml}$ PRP were prepared, as previously described [20].

\section{Case selection and history}

Eight adult Warmblood show jumping horses were included in this study. The horses showed the following clinical signs: acute lameness in one of the front limbs (one of the horses was lame after a jumping exercise), swelling, warmth and sensitivity in the area of the accessory ligament of the deep digital flexor tendon (ALDDFT). Moreover, all lesions of the ALDDFT had to be clearly detectable on ultrasound examination, and none of the horses could have received any treatment before inspection by the non-blinded attending veterinarians. In addition, horses with lesions in other structures, besides the ALDDFT, were excluded from the study.

\section{Treatment protocol}

When desmitis of the ALDDFT was diagnosed, the horses were initially treated conservatively for 5 days with non-steroidal antiinflammatory drugs (NSAIDs), resting, cooling, and a compressive bandage, in order to reduce the swelling of the region and obtain optimal conditions for the intralesional injection. After conservative treatment, an intralesional injection of PRP or Tendo-Cell ${ }^{\circledR}$ was randomly assigned to each horse, and performed using ultrasound guidance. All 8 horses were immobilized (box rest) for 3 weeks, followed by daily walking exercises for 5 to 10 minutes for another 3 weeks. The first follow-up was planned 6 weeks after the injection. A second clinical and ultrasonographic examination was performed at 4 months after treatment.

\section{Evaluation protocol}

The horses were re-evaluated clinically and ultrasonographically 
6 weeks and 4 months after the injection with PRP or Tendo-Cell ${ }^{\circledR}$. The clinical examination consisted of a visual inspection, palpation for the presence of swelling, and/or heat, general inspection of the patient, and a concise lameness evaluation. A thorough ultrasound examination was performed at the lesion site. There were several reasons for performing ultrasonographic diagnoses. The ease, safety and non-invasiveness of this method permitted not only a morphologic in vivo evaluation of the lesions, but, more importantly, an observation over time. Thanks to the technological advances and decreasing equipment cost, this imaging modality is very useful and readily available in practice. Two veterinary practitioners were asked to give a score between 0 and 5 for the ultrasound images of all the patients. The scoring system was adapted from a previous study about superficial digital flexor tendinitis and desmitis of the suspensory ligament by Broeckx et al. [20]. The threshold for improvement after successful conservative therapy was set at maximal $40 \%$ at 6 weeks, and $60 \%$ at 4 months after conservative treatment. A score of 0 corresponded with $0 \%$ improvement or no ultrasonographic improvement; $1=20 \%$ improvement or little ultrasonographic improvement; $2=40 \%$ improvement, or the same ultrasonographic improvement, as expected after 6 weeks of conservative treatment; $3=60 \%$ improvement or better ultrasonographicimprovement, as expected after 6 weeks of conservative treatment, or the same ultrasonographic improvement, as expected after 4 months of conservative treatment; $4=80 \%$ improvement or very good ultrasonographic improvement, much better than seen after 4 months of conservative treatment, but not yet fully recovered; $5=90$ $100 \%$ improvement, or (nearly) no ultrasonographic abnormalities, the ligament has (almost) no hypo-echoic foci, and (nearly) the same fiber orientation as the contralateral ligament. More specific details concerning the scoring system can be found in table 1 .

\section{Results}

\section{Isolation and tenogenic induction of mesenchymal stem cells (MSCs)}

For the blood sampling, the local ethical committee approved the experimental design (EC_2012_001). After 17 days, the first spindle shaped cells were noticed in the culture flasks, and at 21 days after isolation, the cells were trypsinized at approximately $60 \%$ confluency. The isolated cells had a stellate/spindle shaped morphology (Figure 3 ), and fulfilled all the requirements to be typed as mesenchymal stem cells (MSCs) [22]. After 3 days of tenogenic induction, the cells showed a stretched morphology and fiber orientation in vitro (Figure 3 ). The samples were stored in a $-80^{\circ} \mathrm{C}$ ultralow temperature freezer (Haier, Elscolab), and shipped on dry-ice before clinical application. After thawing, an average cell viablility of $85 \%$ was noticed in all the samples. Moreover, it has been reported that frozen equine PB-derived MSCs do not lose their stem cell characteristics [23]. In this regard, the use of frozen tenogenic induced samples was defensible.

\section{Preparation of platelet-rich plasma (PRP)}

Concerning the platelet-rich plasma (PRP) preparation, each sample contained approximately $200 \times 10^{6}$ platelets per $\mathrm{ml}$, and was frozen and stored at $1 \mathrm{ml}$ per sample in a $-80^{\circ} \mathrm{C}$ ultralow temperature freezer (Haier, Elscolab), before clinical application. In addition, it has to be mentioned that for all the Tendo-Cell ${ }^{\circledR}$ and PRP samples, bacteriological, fungal and yeast examinations were performed. Obviously, only the samples that were negative for the microbiological examinations were released for clinical use. In the present study, we decided to work with a liquid form of PRP because; also the stem cells were in a liquid carrier (DMEM). In this regard, we were able to compare Tendo-Cell with PRP, using the same treatment protocol and similar carrier fluids.

\section{Patient follow-up}

In the days following the intralesional injection, particular attention was paid to observing any possible adverse effect or hypersensitivity reaction, which would be noticeable in the form of wheal formation (physical reaction), local warmth, sweating, heavy breathing or fever. In all 8 horses, there were no signs of any of the general adverse effects, which could have been expected, since the horses were injected locally. In contrast with the Tendo-Cell ${ }^{\mathbb{}}$ treated patients, the 4 horses treated with PRP showed a more pronounced swelling during 5 days after injection, which disappeared without medical treatment (Figure 4). At the re-evaluations at 6 weeks and 4 months post injection (Figure 4), none of the horses presented local adverse effects after treatment with PRP or Tendo-Cell ${ }^{\circledR}$ in the accessory ligament of the deep digital flexor tendon (ALDDFT).

All the horses treated with PRP were still lame at approximately 6 weeks post injection, the ALDDFT region was faintly swollen, and ultrasound images were only slightly improved. Therefore, a score $2 / 5$ was given by 2 independent veterinarians to all 4 patients (Table 2 Figure 5). In the Tendo-Cell ${ }^{\circledR}$ treated group, on the other hand, all 4 horses were clinically sound, the swelling disappeared, and the same 2 independent veterinarians gave a score $4 / 5$ for the ultrasound images at 6 weeks after intralesional injection (Table 2, Figure 5). This implicates that the lesions improved about $80 \%$ on the ultrasound images, which was much better than the $40 \%$ improvement in the PRP treated group. Figure 6 represents the ultrasound images of 3 patients, before and 6

\begin{tabular}{|l|l|l|l|}
\hline Score & Echogenicity & $\begin{array}{l}\text { Fiber pattern/alignment } \\
\text { Anechoic area } \\
\text { (central core lesion) }\end{array}$ & $\begin{array}{l}\text { Lacking of parallel pattern } \\
\text { Acute injury (haemorrhage), } \\
0-25 \% \text { FA }\end{array}$ \\
\hline $\mathbf{0}$ & $\begin{array}{l}\text { Lesion site starting to fill with presence of hypo-echoic areas, and moderate diffuse } \\
\text { decrease in echogenicity }\end{array}$ & $\begin{array}{l}\text { Lacking of nice parallel } \\
\text { pattern, } \\
0-25 \% \text { FA }\end{array}$ \\
\hline $\mathbf{2}$ & $\begin{array}{l}\text { Lesion site gradually filling with presence of multiple areas with decreased echogenicity } \\
\text { Increased parallel pattern, } \\
25-50 \% \text { FA }\end{array}$ \\
\hline $\mathbf{3}$ & $\begin{array}{l}\text { Demarcation between injured and uninjured tendon less distinct, } \\
\text { Hypo-echoic areas are remaining }\end{array}$ & $\begin{array}{l}\text { Increased parallel pattern, } \\
25-50 \% \text { FA }\end{array}$ & Enlarged width and thickness \\
\hline $\mathbf{4}$ & $\begin{array}{l}\text { Hardly any demarcation between injured and healthy tissue, } \\
\text { Faint signs of hypo-echoic areas }\end{array}$ & $\begin{array}{l}\text { Close to total fiber alignment, } \\
75-100 \% \text { FA }\end{array}$ \\
\hline $\mathbf{5}$ & $\begin{array}{l}\text { Echogenicity (almost) identical to contralateral ligament } \\
\text { Almost no enlarged width and } \\
\text { thickness }\end{array}$ & $\begin{array}{l}\text { Close to total fiber alignment, } \\
75-100 \% \text { FA }\end{array}$ \\
\hline
\end{tabular}

Table 1: The scoring system used to evaluate and compare the ultrasound images in the present study. Different parameters such as echogenicity, fiber pattern/alignment (FA) grading, and size (width and thickness) of the ligament were considered and compared to the contralateral limb. 
Citation: Beerts C, Seifert C, Zimmerman M, Felix E, Suls M, et al. (2013) Desmitis of the Accessory Ligament of the Equine Deep Digital Flexor Tendon: A Regenerative Approach. J Tissue Sci Eng 4: 125. doi:10.4172/2157-7552.1000125

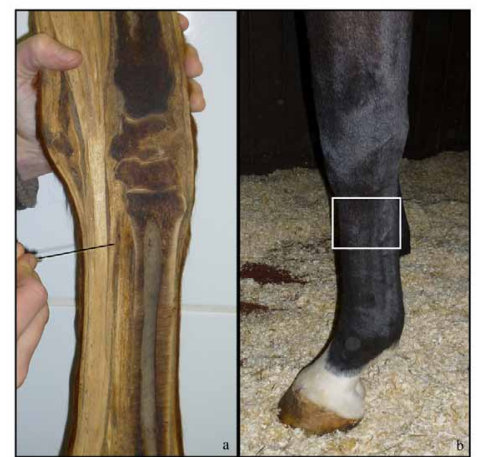

Figure 2: Longitudinal section of a thoracic limb. The accessory ligament of the deep digital flexor tendon is indicated by the black line (a) Left thoracic limb. The region of swelling in case of desmitis of the accessory ligament of the deep digital flexor tendon is situated in the framed area (b).

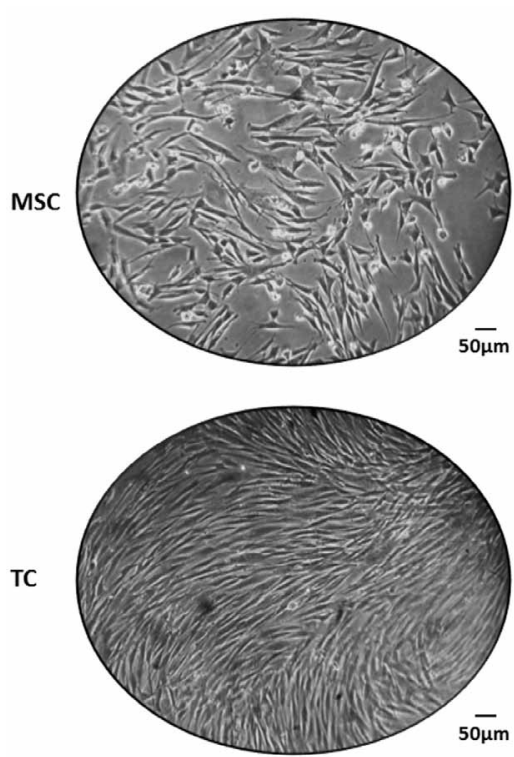

Figure 3: Representative light microscopic images at a 20X magnification of equine peripheral blood (PB)-derived mesenchymal stem cells (MSCs) in their undifferentiated state and after tenogenic induction (Tendo-Cell ${ }^{\circledR}=\mathrm{TC}$ ). In contrast to the spindle shaped morphology of the MSCs, the typical lengthened tenogenic morphology and longitudinal orientation could be noticed in the Tendo-Cell ${ }^{\circledR}$ cultures.

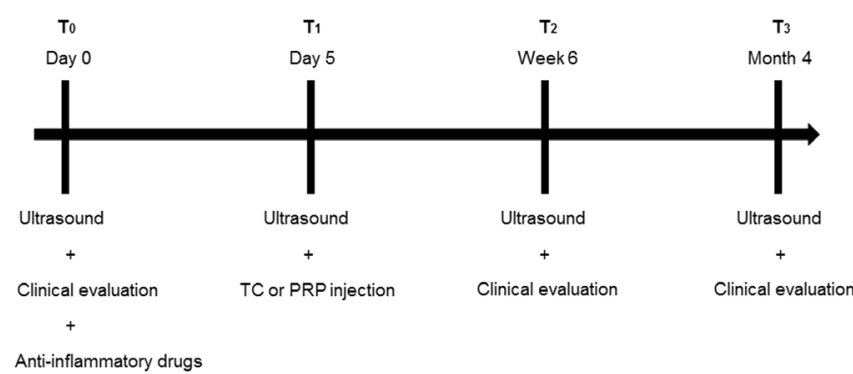

Figure 4: The timeline represents the treatment and follow-up protocol used in the present study at different time points $(T)$. weeks after treatment with Tendo-Cell ${ }^{\circledR}$. A considerable filling of the lesions could be noticed in all cases. Still, the lesions were not completely filled, and therefore, the patients were advised to continue and increase the walking exercise for 3 more weeks, followed by trotting exercise, until 4 months after the treatment.

Four months after the intralesional PRP injections, the horses were faintly lame (only visible under certain circumstances), and the attending veterinarians assigned a score $3 / 5$ (Table 2, Figure 5), which was still not comparable with 6 weeks after Tendo-Cell ${ }^{\circledR}$ treatment. At 4 months after Tendo-Cell ${ }^{\circledR}$ treatment, 3 of the 4 horses received a score $5 / 5$, and went back to full training. However, 1 of the 4 horses slightly relapsed (non-pronounced lameness), and received a score $3 / 5$, as in the PRP group (Table 2, Figure 5).

\section{Discussion}

In the present study, 8 horses with acute desmitis of the accessory ligament of the deep digital flexor tendon (ALDDFT) were treated with 2 different allogenic regenerative therapies: platelet-rich plasma (PRP) or tenogenic induced mesenchymal stem cells (MSCs) (Tendo-Cell ${ }^{\circledR}$ ). In all of the horses $(n=4)$ injected with PRP, only small improvement in the healing was noticed by both attending veterinarians. In this regard, the PRP treated horses were considered as a control group. After

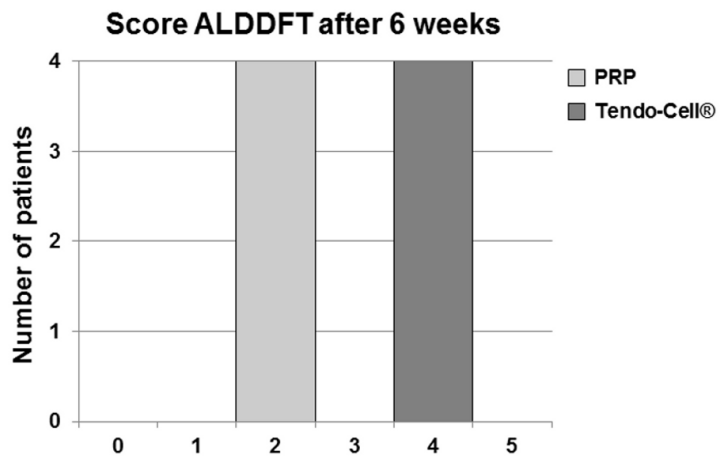

Score ALDDFT after 4 months

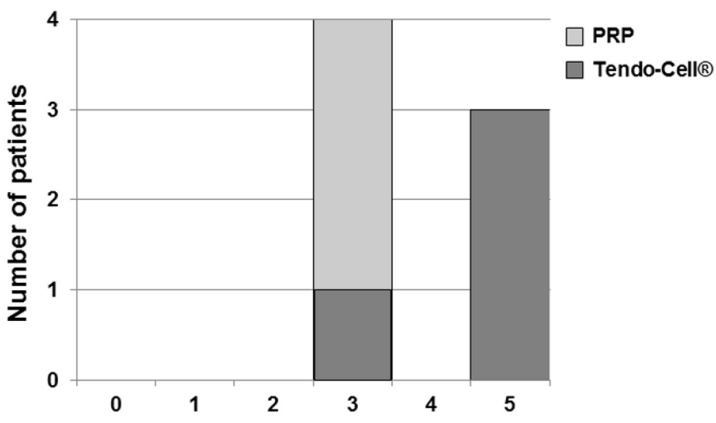

Figure 5: Histograms represent the number of patients, and the different scores they received from the veterinary practitioners (0-5), at approximately 6 weeks and 4 months after treatment of their accessory ligament of the deep digital flexor tendon (ALDDFT). At 6 weeks after treatment with platelet-rich plasma (PRP), all 4 patients (light grey) received a score 2/5. At the same time point, all 4 Tendo-Cell ${ }^{\circledR}$ treated patients (dark grey) received a score $4 / 5$. At 4 months after PRP treatment, all the patients received a score $3 / 5$. Although 1 of the Tendo-Cell ${ }^{\circledR}$ treated patients received the same score, the other 3 patients received a score $5 / 5$. 


\begin{tabular}{|c|c|c|c|c|c|c|c|c|c|}
\hline & Lameness $T_{0}$ & Ultrasound $T_{0}$ & Treatment $T_{0}$ & Ultrasound $T_{2}$ & Lameness $_{2}$ & Score $T_{2}$ & Ultrasound $\mathrm{T}_{3}$ & Lameness $_{3}$ & Score $T_{3}$ \\
\hline H1 & Yes & $20 \%$ & PRP & $40 \%$ & Yes & 2 & $60 \%$ & Yes & 3 \\
\hline $\mathrm{H} 2$ & Yes & $20 \%$ & PRP & $40 \%$ & Yes & 2 & $60 \%$ & Yes & 3 \\
\hline H3 & Yes & $20 \%$ & PRP & $40 \%$ & Yes & 2 & $60 \%$ & Yes & 3 \\
\hline H4 & Yes & $20 \%$ & PRP & $40 \%$ & Yes & 2 & $60 \%$ & Yes & 3 \\
\hline H5 & Yes & $20 \%$ & TC & $80 \%$ & No & 4 & $100 \%$ & No & 5 \\
\hline H6 & Yes & $20 \%$ & TC & $80 \%$ & No & 4 & $100 \%$ & No & 5 \\
\hline H7 & Yes & $20 \%$ & $\mathrm{TC}$ & $80 \%$ & No & 4 & $60 \%$ & Yes & 3 \\
\hline H8 & Yes & $20 \%$ & TC & $80 \%$ & No & 4 & $100 \%$ & No & 5 \\
\hline
\end{tabular}

Table 2: Eight horses $(\mathrm{H})$ with desmitis of the accessory ligament of the deep digital flexor tendon (ALDDFT) were treated: four with platelet-rich plasma (PRP) and four with Tendo-Cell ${ }^{\circledR}(T C)$. Five days before $\left(T_{0}\right)$ and 6 weeks $\left(T_{2}\right)$ and 4 months $\left(T_{3}\right)$ after the treatment, patients were clinically and ultrasonographically examined, and the filling of the lesion was scored by 2 independent veterinarians.

Tendo-Cell ${ }^{\circledR}$ treatment, on the other hand, a more positive evolution was observed clinically, as well as ultrasonographically.

The optimal timing of the intralesional injection with a regenerative medicine remains an issue of debate. On the one hand, it has been reported that it is preferable to inject stem cells during the acute phase, while on the other hand, it has been reported to be beneficial to wait until granulation and vascularisation of the injured tissue have started [14,24]. In the present study, intralesional injections were performed 5 days after conservative treatment with Non-Steroidal Anti-Inflammatory Drugs (NSAIDs), in order to control the acute inflammation, and to provide a more suitable micro-environment for the regenerative therapy.

Following the injection of allogenic PRP, as well as allogenic Tendo-Cell ${ }^{\mathbb{B}}$, no severe immune response was observed in any of the horses, as previously reported for the treatment of 25 horses with lesions in the superficial digital flexor tendon (SDFT) and suspensory ligament (SL) [20]. Although, in this study a mild immune response was noticed in one of the horses treated with PRP, the safe use of allogenic PRP has also been previously reported in humans [25]. Indeed, different studies report that MSCs have the capacity to inhibit the innate immune activation by blocking dendritic cell maturation and suppressing monocyte and T-cell activity, with a significant tumor necrosis factor-alfa (TNF- $\alpha$ ) and interleukin (IL)-6 reduction [2630]. In addition, MSCs would also be able to increase the production of anti-inflammatory agents, such as IL-1 receptor antagonist [30], and IL-10 [31]. In a study established by Guest [32], no visible cell mediated immune response was noticed after an injection of allogenic mesenchymal progenitor cells in a SDFT in horses, and additionally, an integration of injected stem cells within the injured tendon was revealed. Furthermore, Carrade et al. [33,34] demonstrated that, intradermal injections of equine allogenic umbilical cord-derived MSCs in 6 horses, did not induce any hypersensitivity reaction. Nevertheless, it has been reported that major histocompatibility complex (MHC)-Ia and -II (immunogenic) expression would increase, and MHC-Ib (immunosuppressive) expression would reduce in vitro, after differentiating MSCs towards different adult cell types with myogenic, endothelial, or smooth muscle characteristics [35]. Future research should determine whether or not this would be the case after in vivo tenogenic differentiation, and what the influence of MHC II expression would be on possible adverse reactions.

In the present study, at 6 weeks after the intralesional injection, all the horses treated with Tendo-Cell ${ }^{\circledR}$ showed $80 \%$ improvement, or a very good ultrasonographic improvement (score 4/5), with filling and presence of fiber alignment, but not yet a fully recovered ligament. At 4 months after the treatment, 3 out of 4 horses went back in training. One horse relapsed to a score $3 / 5$. This could be attributable to different factors: low intrinsic strength, individual differences, wrong movement during revalidation, trauma in the stable, et cetera. Future research might provide more answers to this question. Of the PRP treated patients, on the other hand, 4 out of 4 received a score of $2 / 5$ at 6 weeks post injection, which corresponds with only $40 \%$ improvement. At 4 months after the treatment, all these patients received a score $3 / 5$, which was still not more than $60 \%$ improvement. Literature reports a varying recovery percentage of horses with desmitis of the ALDDFT, after conservative treatments. According to a first study which included the follow-up of 13 equine patients with uncomplicated desmitis of the ALDDFT, $77 \%$ of the patients $(n=10)$ recovered entirely, within an average recovery period of 6 months after conservative therapy, consisting of box rest, walking exercises and NSAIDs in some cases [36]. On the other hand, Van den Belt et al. [37] reported that, from the 19 horses available for the 36 months follow-up, only 3 horses were able to resume full work after box rest and controlled exercise. This corresponds with $16 \%$ of positive outcomes after conservative treatment. It has to be mentioned though that in the study of Van den Belt [37], 40\% of the horses showed lesions on one of the other soft tissues, reducing the prognosis of these animals. Another study reported $44 \%$ of full recovery after conservative treatment in 18 horses [38]. Moreover, also extracorporal shock wave therapy did not give significant results as a treatment for desmitis of the ALDDFT [13] Finally, in one case treated with an intralesional injection of autologous conditioned plasma, a full recovery was observed after only 7 to 9 months post injection. Taking all the aforementioned conservative treatments together, 21 of the 50 horses with ALDDFT desmitis that were conservatively treated fully recovered after at least 6 months (an average of $42 \%$ ). In comparison with conservative therapies in general, and even PRP treatment in specific, we may conclude that the 3 out of 4 $(75 \%)$ recovery rate at 4 months after the Tendo-Cell ${ }^{\mathbb{B}}$ treatment seems promising. However, since the other studies used different criteria for case selection and another scoring system, any comparison should be interpreted with caution. Moreover, our study should be considered as preliminary data, and in the future, larger case studies with a long term follow-up will have to confirm the sustainability of the ALDDFTs to reinjury. Indeed, desmitis of the ALDDFT is a commonly encountered injury in sport horses, as well as in pleasure riding horses, and to date; few successful treatments have been reported.

On the other hand, the moderate results obtained after intralesional injection with allogenic PRP should be brought under the attention. It could be postulated that for the treatment of desmitis of the ALDDFT, PRP alone is not sufficient to induce an enhanced tenocyte formation, and to subsequently form healthy tissue. In this regard, PRP would be more indicated as an adjuvant to stimulate growth of healthy cells [39], and because of the disturbed micro-environment, the healing effects of a single injection with PRP on damaged cells might be insufficient. Still, different studies indicate the healing enhancing effects of PRP on tendon lesions, because of increasing extracellular matrix synthesis, 
Citation: Beerts C, Seifert C, Zimmerman M, Felix E, Suls M, et al. (2013) Desmitis of the Accessory Ligament of the Equine Deep Digital Flexor Tendon: A Regenerative Approach. J Tissue Sci Eng 4: 125. doi:10.4172/2157-7552.1000125

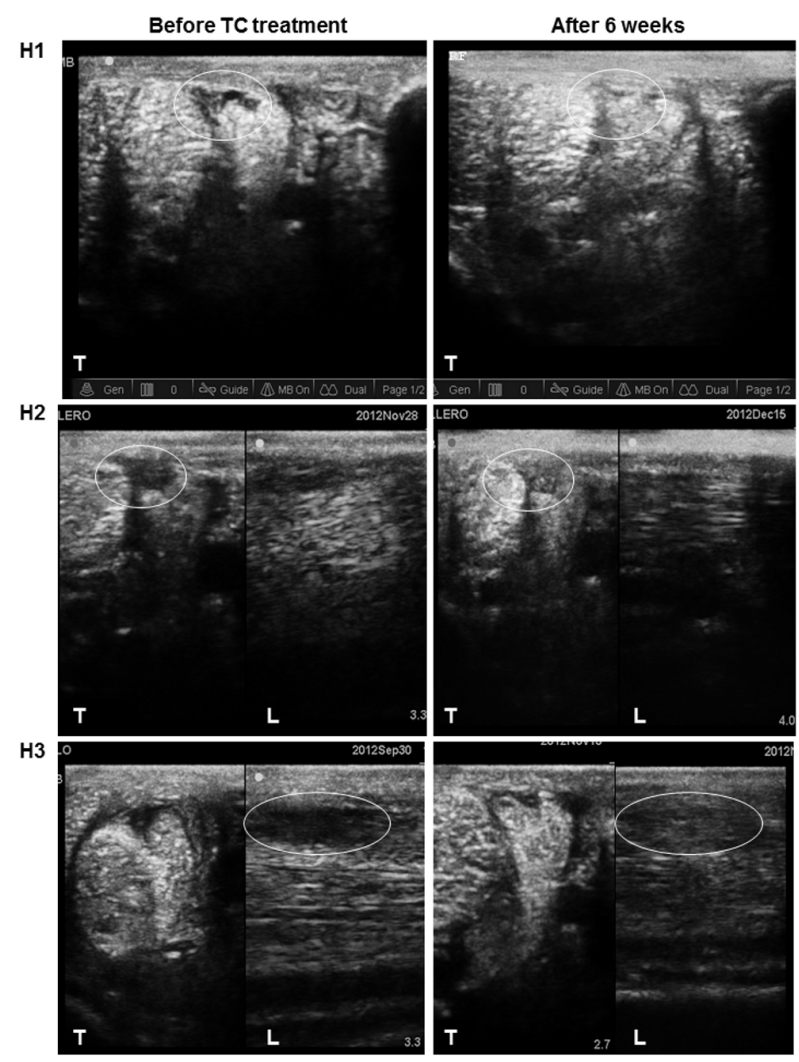

Figure 6: Transversal (T) and longitudinal (L) ultrasound images of a lesion (white circle) in accessory ligament of the deep digital flexor tendon (ALDDFT) in 3 horses $\mathbf{( H )}$ before (left column) and 6 weeks after (right column) treatment with tenogenic induced allogenic mesenchymal stem cells (Tendo-Cell ${ }^{\circledR}=\mathbf{T C}$ ). At approximately 6 weeks after the treatment, a score 4 was given to all the treated ALDDFTs, because although the fiber orientation was completed, there were still some small hypo-echoic zones.

vascular ingrowth promotion and downregulating effects on matrix degrading cytokines [16,40-42]. Nevertheless, also Schnabel described less regenerative effects of PRP than acellular bone marrow in suspensory ligament explant cultures [17].

In conclusion, this study reports a positive clinical and ultrasonographical outcome after tenogenic induced MSC (Tendo$\mathrm{Cell}^{\mathbb{R}}$ ) treatment of desmitis of the equine ALDDFT, whereas no considerable improvements could be noticed after treatment with allogenic PRP.

\section{Acknowledgements}

The authors would like to acknowledge Global Stem Cell Technology and the sources of private funding that have provided the basis for this study.

\section{References}

1. Dyson SJ (2011) Injuries of the accessory ligament of the deep digital flexor tendon. In: Diagnosis and Management of Lameness in the Horse. ElsevierSaunders 734-738.

2. Verwilghen D, Gabriel A, Busoni V, van Galen G, Grulke S, et al. (2009) Equine tendonitis: a review of current therapies. First Part: Tendon structure, tendon lesions and diagnosis. Annales de Médecine Vétérinaire 153: 145-155.

3. Ketchum LD (1979) Tendon healing. In: Fundamentals of wound management in surgery, Hunt TK, Dunphy JE, (eds.). (1stedn), Appleton-Century-Crofts, New York, USA.

4. Kajikawa Y, Morihara T, Watanabe N, Sakamoto H, Matsuda K, et al. (2007)
GFP chimeric models exhibited a biphasic pattern of mesenchymal cell invasion in tendon healing. J Cell Physiol 210: 684-691

5. Spaas JH, Guest DJ, Van de Walle GR (2012) Tendon regeneration in human and equine athletes: Ubi Sumus-Quo Vadimus (where are we and where are we going to)? Sports Med 42: 871-890.

6. Gillis CL (1997) Rehabilitation of tendon and ligament injuries. Proceeding American Association of Equine Practice 43: 306.

7. Dowling BA, Dart AJ, Hodgson DR, Smith RK (2000) Superficial digital flexor tendonitis in the horse. Equine Vet J 32: 369-378.

8. Smith RKW (2011) Pathophysiology of tendon injury. In: Diagnosis and management of lameness in the horse, Ross MW, Dyson SJ, (eds,). (2ndedn), Elsevier-Saunders 694-706.

9. Bowring B, Chockalingam N (2010) Conservative treatment of tibialis posterior tendon dysfunction--a review. Foot (Edinb) 20: 18-26.

10. Henninger R (1994) Treatment of superficial digital flexor tendinitis. Vet Clin North Am Equine Pract 10: 409-424.

11. Lake JE, Ishikawa SN (2009) Conservative treatment of Achilles tendinopathy: emerging techniques. Foot Ankle Clin 14: 663-674.

12. Wilson JJ, Best TM (2005) Common overuse tendon problems: A review and recommendations for treatment. Am Fam Physician 72: 811-818.

13. Waguespack RW, Burba DJ, Hubert JD, Vidal MA, Lomax LG, et al. (2011) Effects of extracorporeal shock wave therapy on desmitis of the accessory ligament of the deep digital flexor tendon in the horse. Vet Surg 40: 450-456.

14. Verwilghen D, Caudron I, van Galen G, Gabriel A, Grulke S, et al. (2010) Equine tendonitis: a review on current therapies. Annales de Médecine Vétérinaire 154: 1-15.

15. Todhunter PG, Schumacher J, Finn-Bodner ST (1997) Desmotomy for treatment of chronic desmitis of the accessory ligament of the deep digital flexor tendon in a horse. Can Vet J 38: 637-639.

16. Schnabel LV, Mohammed HO, Miller BJ, McDermott WG, Jacobson MS, et al. (2007) Platelet rich plasma (PRP) enhances anabolic gene expression patterns in flexor digitorum superficialis tendons. J Orthop Res 25: 230-240.

17. Schnabel LV, Sonea HO, Jacobson MS, Fortier LA (2008) Effects of platelet rich plasma and acellular bone marrow on gene expression patterns and DNA content of equine suspensory ligament explant cultures. Equine Vet J 40: 260265 .

18. Godwin EE, Young NJ, Dudhia J, Beamish IC, Smith RK (2012) Implantation of bone marrow-derived mesenchymal stem cells demonstrates improved outcome in horses with overstrain injury of the superficial digital flexor tendon. Equine Vet J 44: 25-32.

19. Smith RK (2008) Mesenchymal stem cell therapy for equine tendinopathy. Disabil Rehabil 30: 1752-1758.

20. Broeckx S, Zimmerman M, Aerts D, Seys B, Suls M, et al. (2012) Tenogenesis of equine peripheral blood-derived mesenchymal stem cells: in vitro versus in vivo. J Tissue Sci Eng S11: 1-6.

21. Georg R, Maria C, Gisela A, Bianca C (2010) Autologous conditioned plasma as therapy of tendon and ligament lesions in seven horses. J Vet Sci 11: 173 175

22. Spaas JH, De Schauwer C, Cornillie P, Meyer E, Van Soom A, et al. (2013) Culture and characterisation of equine peripheral blood mesenchymal stromal cells. Vet J 195: 107-113.

23. Martinello T, Bronzini I, Maccatrozzo L, lacopetti I, Sampaolesi M, et al. (2010) Cryopreservation does not affect the stem characteristics of multipotent cells isolated from equine peripheral blood. Tissue Eng Part C Methods 16: 771-781.

24. Smith RK, Korda M, Blunn GW, Goodship AE (2003) Isolation and implantation of autologous equine mesenchymal stem cells from bone marrow into the superficial digital flexor tendon as a potential novel treatment. Equine Vet $J$ 35: 99-102.

25. Weber CF (2012) Modern coagulation management reduces the transfusion rate of allogenic blood products. Anasthesiol Intensivmed Notfallmed Schmerzther 47: 418-424.

26. Djouad F, Charbonnier LM, Bouffi C, Louis-Plence P, Bony C, et al. (2007) Mesenchymal stem cells inhibit the differentiation of dendritic cells through an interleukin-6-dependent mechanism. Stem Cells 25: 2025-2032. 
Citation: Beerts C, Seifert C, Zimmerman M, Felix E, Suls M, et al. (2013) Desmitis of the Accessory Ligament of the Equine Deep Digital Flexor Tendon: A Regenerative Approach. J Tissue Sci Eng 4: 125. doi:10.4172/2157-7552.1000125

27. English K, Barry FP, Mahon BP (2008) Murine mesenchymal stem cells suppress dendritic cell migration, maturation and antigen presentation. Immunol Lett 115: 50-58.

28. Di Nicola M, Carlo-Stella C, Magni M, Milanesi M, Longoni PD, et al. (2002) Human bone marrow stromal cells suppress T-lymphocyte proliferation induced by cellular or nonspecific mitogenic stimuli. Blood 99: 3838-3843.

29. Nasef A, Chapel A, Mazurier C, Bouchet S, Lopez M, et al. (2007) Identification of IL-10 and TGF-beta transcripts involved in the inhibition of T-lymphocyte proliferation during cell contact with human mesenchymal stem cells. Gene Expr 13: 217-226.

30. Ortiz LA, Dutreil M, Fattman C, Pandey AC, Torres G, et al. (2007) Interleukin 1 receptor antagonist mediates the antiinflammatory and antifibrotic effect of mesenchymal stem cells during lung injury. Proc Natl Acad Sci U S A 104: $11002-11007$.

31. Németh K, Leelahavanichkul A, Yuen PS, Mayer B, Parmelee A, et al. (2009) Bone marrow stromal cells attenuate sepsis via prostaglandin $\mathrm{E}(2)$-dependent reprogramming of host macrophages to increase their interleukin-10 production. Nat Med 15: 42-49.

32. Guest DJ, Smith MR, Allen WR (2008) Monitoring the fate of autologous and allogeneic mesenchymal progenitor cells injected into the superficial digital flexor tendon of horses: preliminary study. Equine Vet J 40: 178-181.

33. Carrade DD, Affolter VK, Outerbridge CA, Watson JL, Galuppo LD, et al (2011) Intradermal injections of equine allogeneic umbilical cord-derived mesenchymal stem cells are well tolerated and do not elicit immediate or delayed hypersensitivity reactions. Cytotherapy 13: 1180-1192.
34. Carrade DD, Owens SD, Galuppo LD, Vidal MA, Ferraro GL, et al. (2011) Clinicopathologic findings following intra-articular injection of autologous and allogeneic placentally derived equine mesenchymal stem cells in horses. Cytotherapy 13: 419-430.

35. Huang XP, Sun Z, Miyagi Y, McDonald Kinkaid H, Zhang L, et al. (2010) Differentiation of allogeneic mesenchymal stem cells induces immunogenicity and limits their long-term benefits for myocardial repair. Circulation 122: 24192429.

36. Dyson SJ (1991) Desmitis of the accessory ligament of the deep digital flexor tendon: 27 cases (1986-1990). Equine Vet J 23: 438-444

37. van den Belt AJ, Becker CK, Dik KJ (1993) Desmitis of the accessory ligamen of the deep digital flexor tendon in the horse: clinical and ultrasonographic features. A report of 24 cases. Zentralbl Veterinarmed A 40: 492-500.

38. Mcdiarmid AM (1994) Eighteen cases of desmitis of the accessory ligament of the deepdigital flexor tendon. Equine Vet Educ 6: 49-56.

39. Fortier LA, Smith RK (2008) Regenerative medicine for tendinous and ligamentous injuries of sport horses. Vet Clin North Am Equine Pract 24: 191 201.

40. Molloy T, Wang Y, Murrell G (2003) The roles of growth factors in tendon and ligament healing. Sports Med 33: 381-394.

41. Tang JB, Xu Y, Ding F, Wang XT (2003) Tendon healing in vitro: promotion of collagen gene expression by bFGF with NF-kappaB gene activation. J Hand Surg Am 28: 215-220.

42. Kang HJ, Kang ES (1999) Ideal concentration of growth factors in rabbit's flexor tendon culture. Yonsei Med J 40: 26-29. 